\title{
Real-time monitoring of brain energy metabolism in vivo using microelectrochemical sensors: the effects of anesthesia
}

\author{
John P. Lowry ${ }^{\mathrm{a}, *}$, Marianne Fillenz ${ }^{\mathrm{b}}$ \\ ${ }^{a}$ Neurochemistry Research Unit, Bioelectroanalysis Laboratory, Department of Chemistry, National University of Ireland, Maynooth, Co. Kildare, Ireland \\ ${ }^{\mathrm{b}}$ University Laboratory of Physiology, University of Oxford, Parks Road, Oxford OX1 3PT, UK
}

Received 8 February 2001; received in revised form 30 April 2001; accepted 4 May 2001

\begin{abstract}
Rats were implanted in the striatum with a Pt/Ir electrode for measurement of regional cerebral blood flow (rCBF) $\left(\mathrm{H}_{2}\right.$ clearance technique), a carbon paste electrode for monitoring tissue oxygen and a glucose biosensor for monitoring extracellular glucose. Changes in all three parameters were recorded in response to the intraperitoneal (i.p.) administration of the anesthetics chloral hydrate (350 $\mathrm{mg} / \mathrm{kg})$, sodium pentobarbitone $(60 \mathrm{mg} / \mathrm{kg})$ and ketamine $(200 \mathrm{mg} / \mathrm{kg})$. An i.p. injection of normal saline, given as a control for the injection of the anesthetics, produced a parallel increase in $\mathrm{rCBF}$ and tissue oxygen accompanied by a brief decrease in extracellular glucose. Changes in tissue oxygen reflected the changes in rCBF; there was a decrease in both after sodium pentobarbitone, a decrease followed by a rebound after ketamine and a transient increase after chloral hydrate. All three anesthetics produced a decrease in extracellular glucose. The disparity between the changes in glucose and the changes in rCBF and oxygen suggests that during anesthesia, the reduction in extracellular glucose is not due to a reduction in the direct delivery of glucose from the blood vascular system. These results also indicate that levels of enzymatic substrates and mediators, which are intrinsic to the design and operation of amperometric biosensors, are clearly altered in a complex manner by anesthesia and suggest that caution should be exercised in extrapolating data from acute anesthetized experiments to normal physiology. (c) 2001 Elsevier Science B.V. All rights reserved.
\end{abstract}

Keywords: Electrochemical sensors; Extracellular glucose; Tissue oxygen; Cerebral blood flow; Anesthetics; Brain metabolism

\section{Introduction}

The application of electrochemistry in vivo involves the use of amperometric electrodes and voltammetric techniques for the detection of electroactive substances released from, and surrounding, nerve cells [1]. By implanting microelectrochemical sensors in specific brain regions, applying suitable potential profiles and recording the resulting faradic currents, changes in the concentrations of a variety of substances in the extracellular fluid can be monitored with high time resolution. In recent years, the range of species targeted has been extended to include neurochemically important compounds that are either nonelectroactive or only poorly electroactive at analytically useful potentials. This has been achieved through the use of 'first generation' hydrogen peroxide-detecting microelectrochemical biosensors prepared by immobilizing a sensitive and selective oxidoreductase enzyme on, or within

\footnotetext{
* Corresponding author. Tel.: +353-1-708-4633; fax: +353-1-7083815.

E-mail address: john.lowry@may.ie (J.P. Lowry).
}

close proximity of, an amperometric electrode. Extracellular levels of glucose [2-5], lactate [6-8], choline [9-12] and glutamate [13-16] have been measured in 'acute' (i.e. non-recovery) experiments where recording takes place while the animal is still in the stereotaxic frame under the influence of the anesthetic.

We have recently reported a number of investigations of brain energy metabolism carried out in freely moving animals using a specially designed glucose biosensor [1720]. This sensor was prepared by immobilizing glucose oxidase (GOx) onto platinum microelectrodes by trapping the enzyme during electropolymerisation of poly-phenylenediamine (PPD) on the electrode surface. The following properties were characterized in detail both in vitro and in vivo [21-24]: (i) high sensitivity to glucose; (ii) freedom from fouling by endogenous matrix macromolecules (lipids and proteins); (iii) insignificant interference from reducing agents, especially ascorbic acid normally present in high concentration; and (iv) insensitivity to changes in oxygen partial pressure.

In this study, we used these $\mathrm{Pt} / \mathrm{PPD} / \mathrm{GOx}$ glucose biosensors, in combination with other microelectrochemi- 
cal sensors for rCBF and tissue oxygen, to monitor brain metabolism in freely moving animals, before, during and after anesthesia induced using normal induction doses of three commonly used anesthetic agents: chloral hydrate, sodium pentobarbitone and ketamine. The aim of this research work was not only to examine the effect of anesthesia on brain metabolism but also to investigate the effects of anesthesia on baseline concentrations measured using amperometric biosensors. A preliminary account of some of these results has been communicated to the Physiological Society (London) [19].

\section{Materials and methods}

\subsection{Chemicals and solutions}

The enzyme glucose oxidase from Aspergillus niger (EC 1.1.3.4, Grade I) was obtained from Boehringer Mannheim, East Sussex, UK. The o-phenylenediamine (free base), L-ascorbic acid (AA; A.C.S. reagent) and ketamine (hydrochloride) were from Sigma, Dorset, UK. $\mathrm{D}(+)$-Glucose (AnalaR grade) and chloral hydrate were obtained from BDH Laboratory Supplies, Poole, UK. Sodium pentobarbitone $(60 \mathrm{mg} / \mathrm{kg})$ was obtained from Rhône Mérieux, Essex, UK. The $\mathrm{NaCl}, \mathrm{NaH}_{2} \mathrm{PO}_{4}$ and $\mathrm{NaOH}$ (all BDH, AnalaR grade) were used as supplied. Carbon paste was prepared by thoroughly mixing $2.83 \mathrm{~g}$ of carbon powder (UCP-1-M, Ultra Carbon, Bay City, MI, USA) and $1.0 \mathrm{ml}$ of silicone oil (Aldrich Chemical, Dorset, UK, Catalogue No. 17,563-3) [25].

Stock glucose solutions (1 M) for in vitro calibrations were prepared, left for $24 \mathrm{~h}$ at room temperature to allow equilibration of the anomers, and then stored at $4{ }^{\circ} \mathrm{C}$. Stock AA solutions $(100 \mathrm{mM})$ were prepared just before use because of their gradual decomposition. All in vitro experiments were carried out in a standard three-electrode glass electrochemical cell (capacity $25 \mathrm{ml}$ ) in phosphate buffered saline (PBS) solution (20 ml), pH 7.4 (150 mM NaCl, 40 $\mathrm{mM} \mathrm{NaH}{ }_{2} \mathrm{PO}_{4}$ and $40 \mathrm{mM} \mathrm{NaOH}$ ). All solutions were prepared using deoxygenated doubly distilled deionised water.

In in vivo experiments solutions of normal saline $(0.5$ $\mathrm{ml}, 0.9 \% \mathrm{NaCl})$, chloral hydrate $(350 \mathrm{mg} / \mathrm{kg})$, pentobarbitone $(60 \mathrm{mg} / \mathrm{kg})$ and ketamine $(200 \mathrm{mg} / \mathrm{kg})$ were administered i.p.

\subsection{Preparation of electrochemical sensors}

Glucose biosensors were based on the immobilization of glucose oxidase (GOx) on Pt electrodes with the polymer poly(o-phenylenediamine) (PPD). Pt/PPD/GOx cylinder electrodes were prepared from $5 \mathrm{~cm}$ lengths of Teflon-coated platinum/iridium ( $\mathrm{Pt} / \mathrm{Ir} 90 \% / 10 \%)$ wire (125 $\mu \mathrm{m}$ bare diameter, $160 \mu \mathrm{m}$ coated diameter (5-T), Advent Research Materials, Suffolk, UK) following a pre- viously reported procedure [24]. Prior to implantation, all $\mathrm{Pt} / \mathrm{PPD} / \mathrm{GOx}$ electrodes were preconditioned in vitro by continuous recording in $5 \mathrm{mM}$ glucose over a 10 -h period [24]. Electrodes were then calibrated in vitro for both glucose $(0-100 \mathrm{mM})$ and AA $(0-1 \mathrm{mM})$ to ensure selectivity and linearity of response of the sensor for glucose [22].

Carbon paste disk electrodes (CPEs) for tissue $\mathrm{O}_{2}$ measurements were also made from $5 \mathrm{~cm}$ lengths of $5-\mathrm{T}$ Teflon-coated $\mathrm{Pt} / \mathrm{Ir}$ wire [26]. In vitro calibrations for $\mathrm{O}_{2}$ were performed in $\mathrm{N}_{2}$-purged, air-saturated and $\mathrm{O}_{2}{ }^{-}$ saturated solutions where the concentrations of solution $\mathrm{O}_{2}$ were taken as 0,200 [27,28] and $1250 \mu \mathrm{M}$ [27], respectively. The $\mathrm{H}_{2}$ detection electrodes for $\mathrm{rCBF}$ measurements (see Section 2.3) were made from 2-T (50 $\mu \mathrm{m}$ bare diameter, $75 \mu \mathrm{m}$ coated diameter) Teflon-coated $\mathrm{Pt} / \mathrm{Ir}$ wire as reported previously [26].

\subsection{Voltammetric techniques}

Constant potential amperometry (CPA) at $+700 \mathrm{mV}$ was used to oxidise the enzymatically produced $\mathrm{H}_{2} \mathrm{O}_{2}$ at the $\mathrm{Pt} / \mathrm{PPD} / \mathrm{GOx}$ electrodes in vitro (vs. an SCE reference electrode) and in vivo (vs. implanted $\mathrm{Ag}$ reference electrode, see Section 2.4). Changes in $\mathrm{O}_{2}$ at CPEs were monitored using differential pulse amperometry (DPA). For $\mathrm{O}_{2}$ reduction, two equally sized cathodic pulses were applied, the first from a resting potential at -150 to -350 $\mathrm{mV}$, which corresponds to the foot of the reduction wave for $\mathrm{O}_{2}$ at lipid-modified CPEs, and the second from -350 to $-550 \mathrm{mV}$, which corresponds to the peak of the reduction wave. The difference in the current $(\Delta I)$ sampled during these respective pulse pairs was calculated and changes in $\Delta I$ were used as a measure of changes in $\mathrm{O}_{2}$, which have been shown to be interference-free [29]. Because the CPE has a significant capacitance (background), current (mean value: $-244.8 \pm 59.7 \mathrm{nA}, n=23$ ) changes in the signal cannot be calculated as a percentage [26]. Measurements of rCBF were performed using the $\mathrm{H}_{2}$ clearance technique. $\mathrm{CPA}$ at $+250 \mathrm{mV}$ was used for $\mathrm{H}_{2}$ oxidation. The methods of $\mathrm{H}_{2}$ administration and analysis used in these experiments have been described in detail in a previous publication [26]. Briefly, the gas was administered to the animals by simply holding PEEK tubing (i.d. $1.6 \mathrm{~mm}$, o.d. $3.2 \mathrm{~mm}$; Anachem, UK) under the animal's snout for 10-20 s. This was tolerated extremely well by the rats, which exhibited normal behaviour while it was taking place. The tubing was connected through a flashback arrestor and a pressure regulator to $\mathrm{a}_{2}$ cylinder (zero grade, British Oxygen, UK), with the gas flow controlled external to the rat's bowl. The gas was administered at approximately 5-min intervals and at a flow rate of $150 \mathrm{ml} / \mathrm{min}$. Blood flow measurements were performed by starting the data acquisition (LabVIEW) program and recording the baseline for $5 \mathrm{~s} . \mathrm{H}_{2}$ was then administered until the current had increased by 30-80 nA. The decay 
curve was collected for a 3-min period. The first 30-60 s of the curve was neglected and the remaining 120-240 s were transferred to an analysis program. Here, a first-order analysis plot of $\ln \left[i(t)-i_{\text {baseline }}\right]$ vs. time $t$ was performed. If a linear plot was obtained, the slope was converted to blood flow. When the semi-log plot showed a clear break in the slope, the decay curves before and after the break point were analysed separately.

\subsection{Surgical procedures}

Male Sprague-Dawley rats weighing 200-300 g were anesthetized, following published guidelines [30], with a mixture of Hypnorm (Fentanyl citrate/Fluanisone, Janssen Pharmaceuticals, Oxford, UK), Hypnovel (Midazolam, Roche Products, Herts, UK) and sterile water, mixed 1:1:2 and injected i.p. at a volume of $3.3 \mathrm{ml} / \mathrm{kg}$, as described previously [17,31]. Once surgical anesthesia was established, animals were placed in a stereotaxic frame and the electrodes implanted following a previously described procedure [17]. Because the administration of $\mathrm{H}_{2}$ caused interference problems at the $\mathrm{Pt} / \mathrm{PPD} / \mathrm{GOx}$ electrodes, animals were implanted with either one of two combinations of sensors: (i) a Pt/PPD/GOx electrode, for monitoring glucose, was implanted in the right striatum (coordinates with the skull leveled between bregma and lambda were: $\mathrm{A} / \mathrm{P}+1.0$ from bregma, $\mathrm{M} / \mathrm{L}+2.5$ and $\mathrm{D} / \mathrm{V}$ -8.5 from dura [32], and a carbon paste electrode, for monitoring tissue oxygen, in the left striatum (coordinates: $\mathrm{A} / \mathrm{P}+1.0$ from bregma, $\mathrm{M} / \mathrm{L}-2.5$ and $\mathrm{D} / \mathrm{V}-5.0$ from dura); (ii) a 2-T Pt/Ir electrode, for monitoring $\mathrm{rCBF}$ by the $\mathrm{H}_{2}$ clearance method, was implanted in the right striatum (coordinates: $\mathrm{A} / \mathrm{P}+1.0$ from bregma, $\mathrm{M} / \mathrm{L}$ +2.5 and $\mathrm{D} / \mathrm{V}-8.5$ from dura), and a carbon paste electrode, for monitoring tissue oxygen, in the left striatum (coordinates: $\mathrm{A} / \mathrm{P}+1.0$ from bregma, $\mathrm{M} / \mathrm{L}-2.5$ and $\mathrm{D} / \mathrm{V}-5.0$ from dura).

A reference electrode (8-T Ag wire, $200 \mu \mathrm{m}$ bare diameter; Advent Research Materials) was placed in the cortex, an auxiliary electrode (8- $\mathrm{T} \mathrm{Ag}$ wire) placed between the skull and dura, and an earth wire (8-T Ag wire) attached to one of the support screws. The reference potential provided by the $\mathrm{Ag}$ wire in brain tissue is very similar to that of the SCE [33]. The electrodes and probe were fixed to the skull with dental screws and dental acrylate (Associated Dental Products, Swindon, UK). Surgery typically lasted $40 \mathrm{~min}$ and anesthesia was reversed by an i.p. injection of naloxone $(0.1 \mathrm{mg} / \mathrm{kg}$, Sigma). Post-operative analgesia was provided in the form of a single injection $(0.1 \mathrm{mg} / \mathrm{kg}, \quad$ s.c. $)$ of Vetergesic (Buprenorphine hydrochloride, Reckitt and Colman Pharmaceuticals, Hull, UK) given immediately following the surgery. Animals were allowed to recover after surgery and were assessed for good health according to published guidelines [34] immediately after recovery from anesthesia and at the beginning of each day. This work was carried out under license in accordance with the Animals (Scientific Procedures) Act, 1986.

\subsection{Experimental conditions}

Rats were housed in large plastic bowls (diameter ca. $50 \mathrm{~cm}$ ), in a windowless room under a 12-h light, 12-h dark cycle, lights coming on at 8:00 a.m., with free access to water. Food was available ad libitum. All experiments were carried out with the animal in its home bowl. Implanted electrodes were connected to the potentiostat at least $60 \mathrm{~min}$ prior to the start of each experiment, through a six-pin Teflon socket, and a flexible screened six-core cable, which was mounted through a swivel above the rat's head (Semat Technical, Herts, UK). This arrangement allowed free movement of the animal. Once the background currents for the various sensors had stabilized (typically 30-45 min for the Pt/PPD/GOx glucose electrodes, 5-10 min for the $\mathrm{O}_{2}$ CPEs, and $30 \mathrm{~min}$ for the $\mathrm{rCBF} \mathrm{Pt} / \mathrm{Ir}$ electrodes), experiments were begun. All signals were recorded at 2-s intervals (see Section 2.6).

\subsection{Instrumentation and software}

A low-noise potentiostat (Biostat II, Electrochemical and Medical Systems, Newbury, UK) was used in all experiments. For CPA experiments, either a Macintosh IIx computer or a Mitac 486 PC was used with data acquisition performed using National Instruments (NI, National Instruments, Austin, TX, USA) multifunction data acquisition boards: NB-MIO-16X (Macintosh) and AT-MIO-16 (PC). Further noise reduction was achieved by averaging 75 (Mac) and 100 (PC) determinations to give 1 data point every 2 s. For DPA experiments, all data acquisition was performed on a Mitac 486 PC with data sampling performed at a rate of 250 determinations / pulse and averaged to give 1 data point/pulse [29]. A complete pulse sequence was performed every $2 \mathrm{~s}$. All experiments were performed using in-house developed software: PC (LabWindows, NI version 2.1); Macintosh (LabVIEW, NI version 2.2.1). All analyses were performed using both in-house developed software and the commercial packages Igor Pro 2.0 (WaveMetrics, OR, USA) and Prism (GraphPad Software, CA, USA).

The significance of differences observed was estimated using the Student's $t$-test for paired observations (StatView, Abacus Concepts, CA, USA). Two-tailed levels of significance were used and $P<0.05$ was considered to be significant. All data are presented as mean \pm S.E.M.

\section{Results}

\subsection{Effect of saline injection}

Since the anesthetics were administered by i.p. injection, we first examined the effect of i.p. injection of 
normal saline ( $\mathrm{NaCl} 0.9 \%)$. A typical example of changes in $\mathrm{rCBF}$, tissue oxygen and extracellular glucose is shown in Fig. 1.

There was an immediate increase in $\mathrm{rCBF}$ and oxygen following injection. rCBF increased by $30 \pm 11 \mathrm{ml} / 100$ $\mathrm{g} / \mathrm{min}$ from a baseline of $79 \pm 6 \mathrm{ml} / 100 \mathrm{~g} / \min (n=6)$.
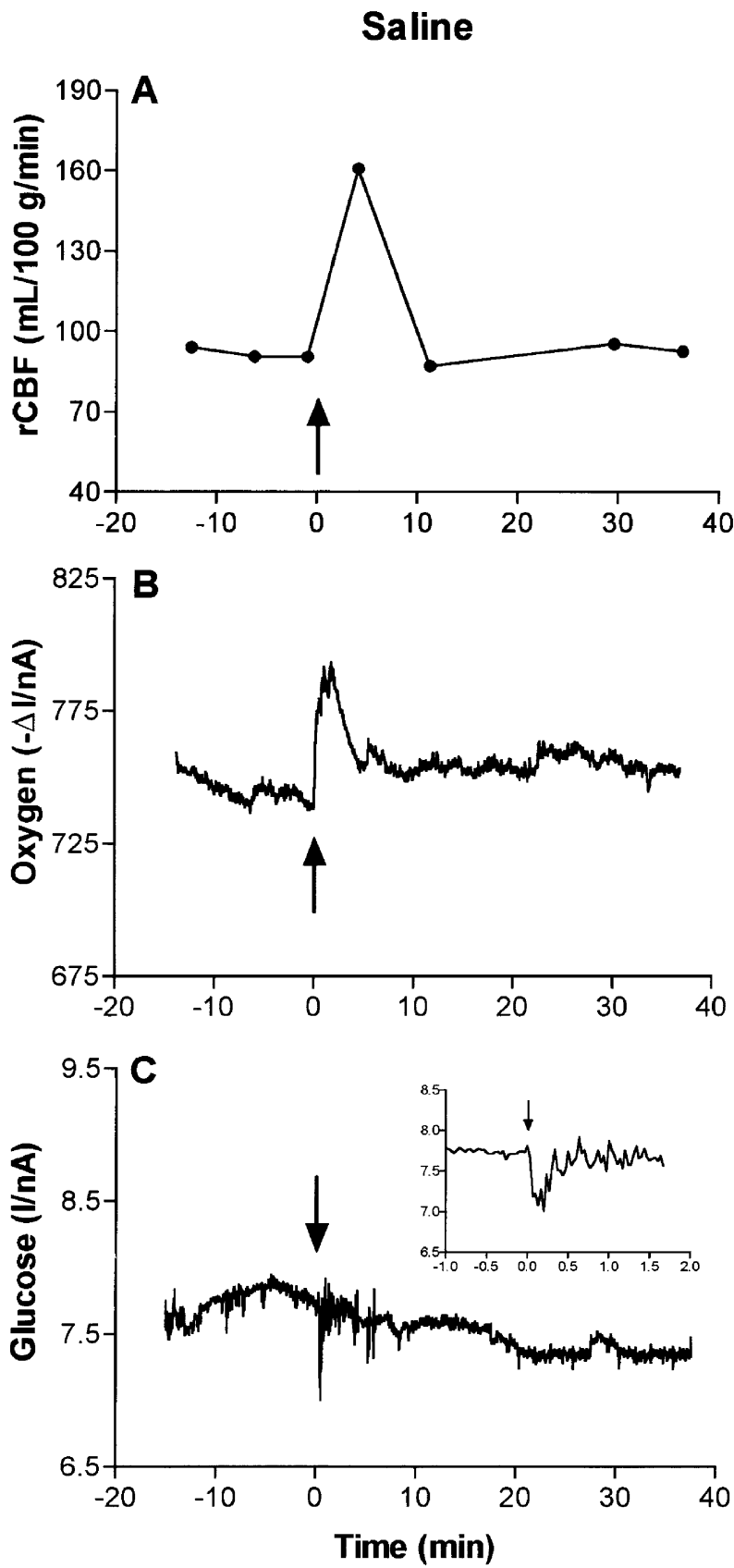

Fig. 1. A typical example of the effect of intraperitoneal injection of normal saline $(0.5 \mathrm{ml}, \mathrm{NaCl} 0.9 \%)$ on A regional cerebral blood flow (rCBF), $\mathbf{B}$ tissue oxygen, and $\mathbf{C}$ extracellular glucose, monitored with a $\mathrm{Pt} / \mathrm{Ir}\left(\mathrm{H}_{2}\right.$ clearance) electrode, a carbon paste electrode, and a glucose biosensor respectively, in the striatum of freely moving rats. Inset: Close-up of the Pt/PPD/GOx glucose signal recorded during the saline injection. Arrows indicate the points of injection.
This represents an increase of $35 \pm 11 \%$. The oxygen signal increased maximally by $13.5 \pm 3.7 \mathrm{nA}$ at $2.5 \pm 0.4$ $\mathrm{min}$ and had returned to baseline by $4.1 \pm 3.7 \mathrm{~min}(n=4)$. This increase in current corresponds to an increase in concentration of $50 \pm 15 \mu \mathrm{M}$ based on calculations from in vitro calibration curves. Because measurements of $\mathrm{rCBF}$ are carried out at 5-min intervals, the duration of the changes in $\mathrm{rCBF}$ for injection of normal saline cannot be determined accurately. By contrast, the carbon paste electrode gives a continuous measurement of oxygen current. The latter can be used as an index of the increase in $\mathrm{rCBF}$ [26] and therefore provides an accurate measure of the duration of the rCBF increase.

The glucose electrode also gives a continuous signal (for extracellular glucose) and provides an accurate measure of the duration of any changes [18]. On injection of normal saline, it exhibited a very brief decrease of $1.2 \pm 0.4$ $\mathrm{nA}$ from a baseline of $7.2 \pm 1.6 \mathrm{nA}(n=5)$. This represents a percentage decrease of $20 \pm 7 \%$ and corresponds to a change in concentration of $34 \pm 7 \mu \mathrm{M}$. The duration of the decrease was $0.7 \pm 0.2 \mathrm{~min}$.

For all three parameters, there was no significant difference in the baseline signals before and after the brief injection effects with the baseline values remaining stable for up to 40-min post injection: $P=0.6317$ (rCBF), $P=$ 0.3882 (oxygen), $P=0.2254$ (glucose).

\subsection{Effect of anesthetics}

The intraperitoneal injection of each of the anesthetic agents produced the same initial response as the i.p. saline injection; a brief increase in rCBF and oxygen and an even shorter decrease in glucose. This was followed by slower more long-lasting changes, which accompanied the behavioral changes associated with anesthesia. The duration of anesthesia as measured by reflex responses (palpebral, corneal and withdrawal reflexes) and spontaneous movements of the rats were similar for the three anesthetics at the doses (see Section 2.1) used: $92 \pm 6 \min (n=10)$ for chloral hydrate, $90 \pm 6 \min (n=7)$ for pentobarbitone and $78 \pm 4 \min (n=11)$ for ketamine.

\subsection{Chloral hydrate}

Chloral hydrate (see Fig. 2) produced a sharp increase in $\mathrm{rCBF}$ from $90 \pm 12 \mathrm{ml} / 100 \mathrm{~g} / \mathrm{min}$ to a maximum of $266 \pm 65 \mathrm{ml} / 100 \mathrm{~g} / \mathrm{min}(P<0.05, n=5)$ at $18 \pm 2 \mathrm{~min}$ after the administration of the anesthetic. This represents a percentage increase of $201 \pm 60 \%$. It then declined to control levels, which it reached when the rats began to show recovery from the anesthesia. The changes in oxygen current closely followed the changes in rCBF. There was a maximum increase in oxygen current of $18.7 \pm 3.1 \mathrm{nA}$ 


\section{Chloral Hydrate}
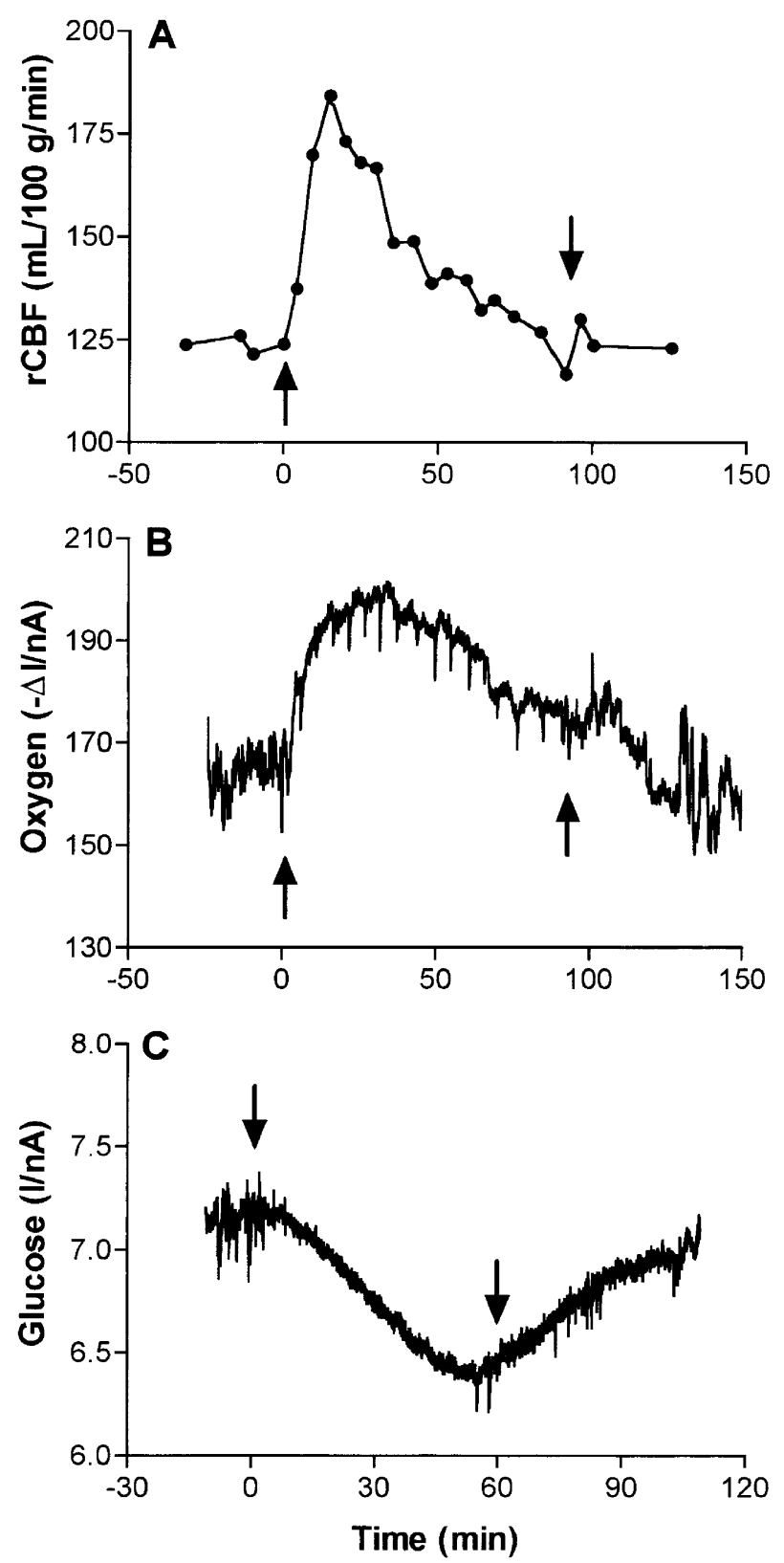

Fig. 2. A typical example of the effect of intraperitoneal injection of chloral hydrate $(350 \mathrm{mg} / \mathrm{kg}$ ) on A regional cerebral blood flow (rCBF), $\mathbf{B}$ tissue oxygen, and $\mathbf{C}$ extracellular glucose, monitored in rat striatum. Arrows indicate the points of injection of, and recovery from, the anesthetic.

$(P<0.03, n=10)$ at $11.6 \pm 1.9 \mathrm{~min}$. This corresponds to an increase in concentration of $69 \pm 9 \mu \mathrm{M}$.

The change in glucose by contrast was in a different direction. Chloral hydrate caused a maximum decrease in glucose current of $2.3 \pm 0.5 \mathrm{nA}$ from a baseline of $8.6 \pm 1.1$ nA $(P<0.02, n=5)$ at $64 \pm 7 \mathrm{~min}$. This represents a decrease of $26 \pm 5 \%$, and corresponds to a change in concentration of $80 \pm 18 \mu \mathrm{M}$ from a baseline value of $311 \pm 50 \mu \mathrm{M}$.

\subsection{Sodium pentobarbitone}

Sodium pentobarbitone (see Fig. 3) produced a steep decrease in rCBF from a baseline of $107 \pm 14 \mathrm{ml} / 100$ $\mathrm{g} / \mathrm{min}$ to a minimum of $64 \pm 16 \mathrm{ml} / 100 \mathrm{~g} / \mathrm{min}(P<$ $0.04, n=3)$ at $42 \pm 4 \mathrm{~min}$ after the administration of the anesthetic. This represents a percentage decrease of $34 \pm$ $7 \%$. This was followed by a slow recovery that failed to reach control levels $2 \mathrm{~h}$ after initial administration of the anesthetic, when rats showed full behavioral recovery. The

\section{Sodium Pentobarbitone}
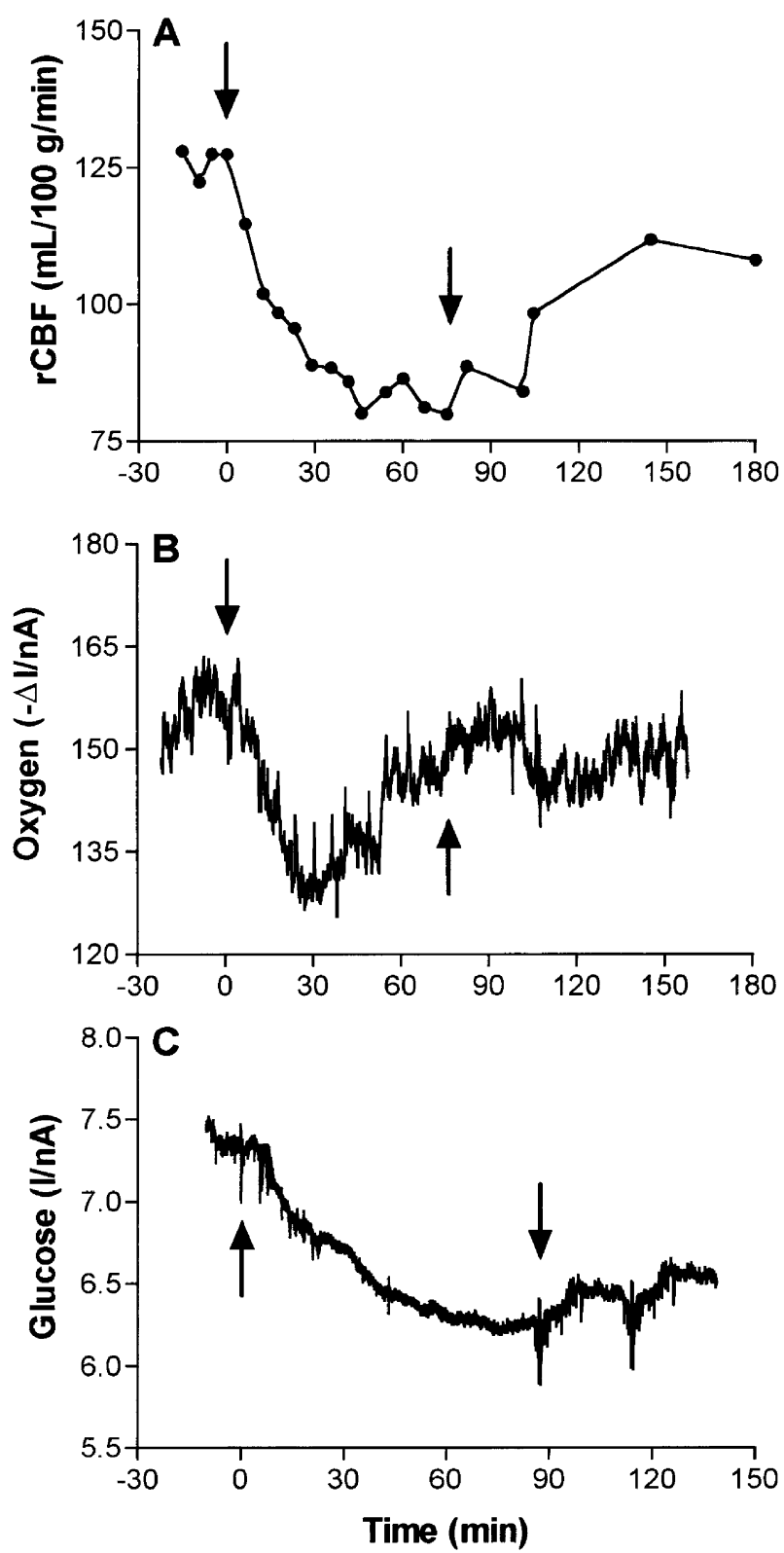

Fig. 3. A typical example of the effect of intraperitoneal injection of sodium pentobarbitone $(60 \mathrm{mg} / \mathrm{kg})$ on A regional cerebral blood flow (rCBF), $\mathbf{B}$ tissue oxygen, and $\mathbf{C}$ extracellular glucose, monitored in rat striatum. Arrows indicate the points of injection of, and recovery from, the anesthetic. 
changes in oxygen current closely followed the changes in rCBF. There was a maximum decrease in oxygen current of $21.4 \pm 5.6 \mathrm{nA}(P<0.02, n=6)$ at $27 \pm 4 \mathrm{~min}$. This represents a decrease of $67 \pm 13 \mu \mathrm{M}$.

The change in glucose was in the same direction. Pentobarbitone caused a maximum decrease in glucose current of $1.7 \pm 0.4 \mathrm{nA}$ from a baseline of $7.1 \pm 0.5 \mathrm{nA}$ $(P<0.04, n=4)$ at $54 \pm 9 \mathrm{~min}$. This represents a de-
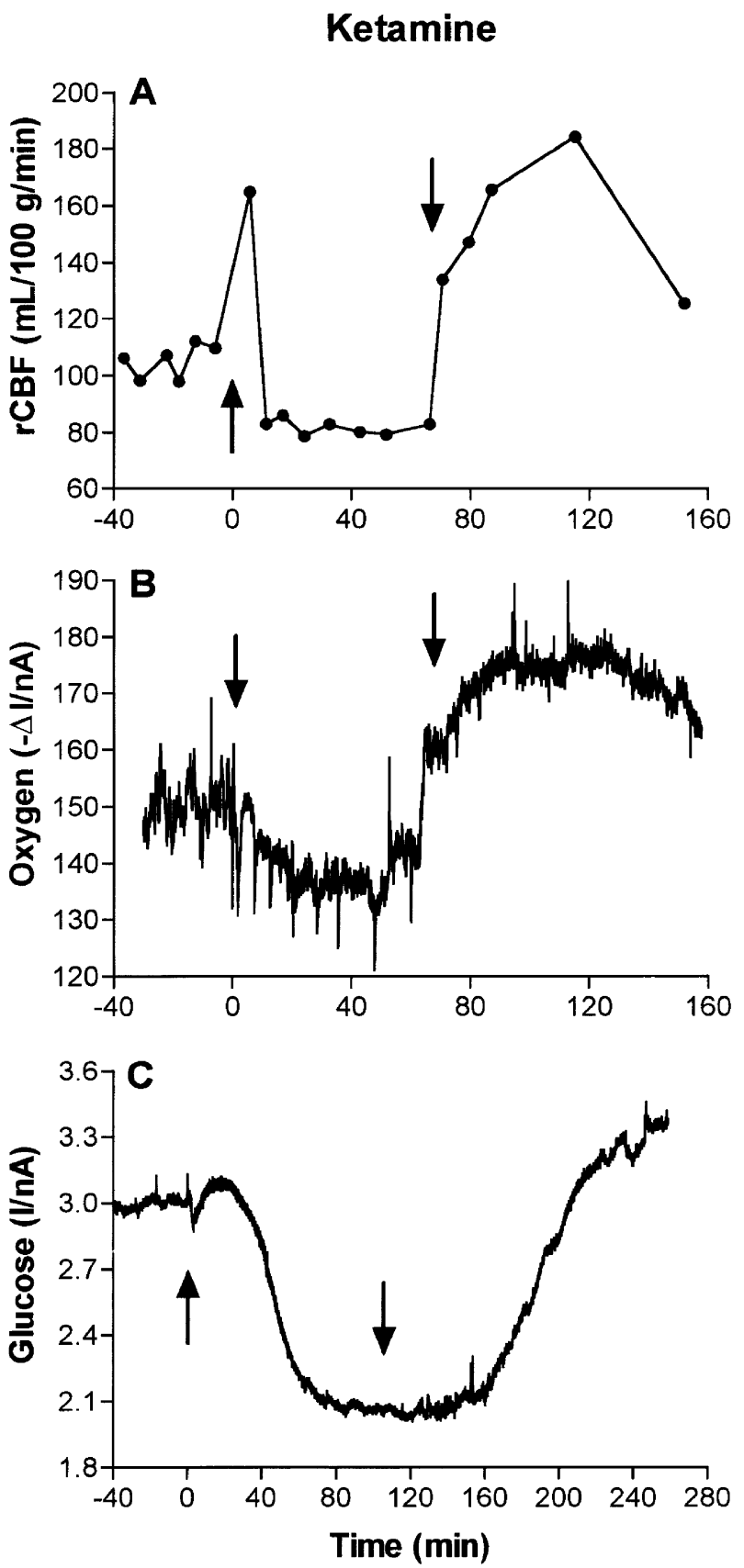

Fig. 4. A typical example of the effect of intraperitoneal injection of ketamine $(200 \mathrm{mg} / \mathrm{kg})$ on A regional cerebral blood flow (rCBF), B tissue oxygen, and $\mathbf{C}$ extracellular glucose, monitored in rat striatum. Arrows indicate the points of injection of, and recovery from, the anesthetic. crease of $25 \pm 8 \%$, and corresponds to a change in concentration of $64 \pm 19 \mu \mathrm{M}$ from a baseline concentration of $258 \pm 17 \mu \mathrm{M}$.

\subsection{Ketamine}

Ketamine (see Fig. 4) produced a biphasic change in $\mathrm{rCBF}$; there was an initial decrease from $93 \pm 8 \mathrm{ml} / 100$ $\mathrm{g} / \mathrm{min}$ to a minimum of $75 \pm 5 \mathrm{ml} / 100 \mathrm{~g} / \mathrm{min}(P<0.01$, $n=5)$ at $20 \pm 2 \mathrm{~min}$, followed by a rapid rebound to a maximum of $156 \pm 18 \mathrm{ml} / 100 \mathrm{~g} / \min (P<0.01, n=5)$ at $93 \pm 9 \mathrm{~min}$ after drug administration. This represents a decrease of $19 \pm 2 \%$ and an increase of $65 \pm 6 \%$, respectively. The rebound accompanied intense motor activity as the rats were recovering from the anesthesia. The changes in oxygen current closely followed the changes in rCBF. There was a maximum decrease in oxygen current of $11.7 \pm 1.9 \mathrm{nA}(P<0.02, n=7)$ at $18 \pm 7 \mathrm{~min}$. This represents a decrease of $43 \pm 11 \mu \mathrm{M}$. The rebound was $15.4 \pm 3.8 \mathrm{nA}(P<0.02, n=7)$ at $88 \pm 10 \mathrm{~min}$. This represents an increase of $41 \pm 6 \mu \mathrm{M}$.

The change in glucose was in the same direction. Ketamine caused a maximum decrease in glucose current of $1.6 \pm 0.3 \mathrm{nA}$ from a baseline of $8.6 \pm 3.2 \mathrm{nA}(P<0.01$, $n=6)$ at $54 \pm 6 \mathrm{~min}$. This represents a percentage decrease of $24 \pm 6 \%$, and corresponds to a change in concentration of $95 \pm 39 \mu \mathrm{M}$ from a baseline value of $316 \pm 61$ $\mu \mathrm{M}$.

\section{Discussion}

Chloral hydrate, sodium pentobarbitone and ketamine are three commonly used non-volatile anesthetic agents for animal surgery. They cause general CNS depression with different mechanisms of action. Chloral hydrate is rapidly metabolized into trichloroethanol and trichloroacetic acid [35]. Trichloroethanol is suspected to be the active substance for inducing anesthesia [36] because, similar to barbiturates, it has the ability to prolong chloride influx induced by exogenous GABA [37]. Sodium pentobarbitone is a lipophilic compound, which acts on the $\mathrm{GABA}_{\mathrm{A}}$ receptor inducing anesthesia by enhancing GABA-mediated transmission [38]. Ketamine causes an anesthetic state that is mediated by non-competitive inhibition of NMDA receptors [39].

A detailed literature survey of previous investigations of the effects of anesthesia on brain energy metabolism reveals a limited number of studies monitoring different metabolic parameters. It has been shown that both pentobarbitone and chloral hydrate cause a lowering of systemic blood pressure [40] and a decrease in glucose utilization [41,42]. Pentobarbitone reduces cerebral blood flow [43,44], whereas for ketamine, both a decrease [45] and an increase [46] have been reported. Based on the accumulation of 
radiolabelled glucose, it has also been estimated that there is little increase in extracellular glucose in pentobarbitone anesthesia [43]. Fellows et al. [47] reported the effect of chloral hydrate $(500 \mathrm{mg} / \mathrm{kg}$ i.p. $)$ on dialysate glucose levels in rat striatum and observed a rapid sustained increase. However, microdialysis (non-quantitative) provides only an indirect measure of extracellular glucose, which depends on the in vivo recovery of the microdialysis probe. This cannot be derived from the in vitro probe recovery [48]. To the best of our knowledge, there are no previous real-time measurements of the effects of anesthesia on extracellular brain glucose concentrations.

The hydrogen clearance technique, used in the present study, provides a direct measure of $\mathrm{rCBF}$ in absolute units. The oxygen and glucose currents are continuous measurements and represent the balance between supply and utilization. Since the changes in oxygen are parallel to the changes in $\mathrm{rCBF}$, we propose that they represent changes in blood flow. The immediate effect of the i.p. injection, whether saline or anesthetic, is similar to the effect of neuronal activation described in our previous paper [17], where during the 5-min period of stimulation (tail pinch), there is an increase in $\mathrm{rCBF}$ and oxygen current and a decrease in extracellular glucose. The latter decrease was followed by a delayed increase during which both $\mathrm{rCBF}$ and oxygen had returned to basal levels; with the brief stimulus of the i.p. injection, the delayed increase in extracellular glucose was absent.

There was an immediate increase in $\mathrm{rCBF}$ and oxygen and a decrease in glucose following saline injection. The increase in $\mathrm{rCBF}$ occurred in only the first of the 5-min measurements after the injection and there was a return to a stable baseline by the next one. The effect of the injection on oxygen and glucose was also brief being less than $4 \mathrm{~min}$ for oxygen and less than $1 \mathrm{~min}$ for glucose. Thereafter, the baseline values remained stable for the duration of recording (ca. 40-min post injection effect, see Fig. 1). Similar initial and brief injection effects have also been observed during the injection of the anesthetic agents, with a comparable return to baseline levels occurring before the effect of the anesthetic takes place and the animal becomes anesthetized [19]. The stress of the i.p. injection stimulates neuronal activation [49], increasing $\mathrm{rCBF}$ and oxygen, and decreasing glucose through an increase in neuronal glucose utilization.

Although with all three anesthetics extracellular glucose was reduced, the relationship between glucose and $\mathrm{rCBF}$ differed between the anesthetics. While the reduction in both glucose and $\mathrm{rCBF}$ after pentobarbitone suggests a reduction in glucose supply, the decrease in glucose accompanied by a transient increase in rCBF after chloral hydrate suggests an increase in glucose utilization. This is supported by reports that chloral hydrate causes an increase in the basal firing rate of dopaminergic neurons in the substantia nigra [50,51], and a recent real-time in vivo voltammetric study where increased release of dopamine in the striatum was reported after chloral hydrate administration [52]. However, the effect of chloral hydrate on striatal dopamine release is controversial; microdialysis experiments have been reported where no change in basal levels [53] and where a decrease in basal levels [54] were observed.

The difference, not only in direction but also in time course, between the changes in rCBF and glucose, is clearly shown in Figs. 2, 3 and 4: the changes in rCBF and oxygen are always parallel and have the same time course. The change in glucose by contrast is in a different direction after chloral hydrate and although in the same direction after pentobarbitone and ketamine is very much slower. The classical model of brain metabolism suggests that glucose is supplied to the extracellular compartment directly from the cerebrovascular compartment; changing energy requirements in this model are met by changes in local cerebral blood flow and there is close coupling between glucose delivery and blood flow [55]. The observed disparity between the changes in glucose and the changes in $\mathrm{rCBF}$ and oxygen suggests that extracellular glucose in the brain is not derived directly from the blood vascular system but must come from some other intermediate compartment. Recent evidence suggests that this is likely to represent astrocytes, which now appear to play a central role in the delivery of metabolic substrates [56].

Several studies have previously been carried out comparing experiments performed in conscious and anesthetized rats indicating significant differences resulting from the effects of the different anesthetics investigated. These have focused on dopamine, DOPAC, 5-HT and HVA and have primarily involved the use of microdialysis techniques [36,53,54,57], although some voltammetric studies of dopamine have been made with carbon paste [58] and carbon fiber electrodes [52]. Recently, several groups have used in vivo voltammetry with 'first generation' amperometric enzyme-based biosensors to monitor brain extracellular levels of several non-electroactive analytes under anesthesia in acute experiments [2-5,7-16]. The findings of the present experiments suggest that caution must be exercised in extrapolating results from such acute experiments to the conscious state. This is especially true for estimations of basal concentrations, as extracellular levels of enzymatic substrates are clearly altered in a complex manner by anesthesia.

\section{Acknowledgements}

JPL gratefully acknowledges Enterprise Ireland (Basic Research Grants Scheme 1999, Grant No. SC/99/149), the Health Research Board (EQN12/2000), and the National University of Ireland, Maynooth (New Researcher Award) for financial support. 


\section{References}

[1] R.D. O'Neill, J.P. Lowry, M. Mas, Monitoring brain chemistry in vivo: voltammetric techniques, sensors and behavioral applications. Crit. Rev. Neurobiol. 12 (1998) 69-127.

[2] I.A. Silver, M. Ereciñska, Extracellular glucose concentration in mammalian brain: continuous monitoring of changes during increased neuronal activity and upon limitation in oxygen supply in normo-, hypo-, and hyperglycemic animals. J. Neurosci. 14 (1994) $5068-5076$.

[3] L.I. Netchiporouk, N.F. Shram, N. Jaffrezic-Renault, C. Martelet, R. Cespuglio, In vivo brain glucose measurements: differential normal pulse voltammetry with enzyme-modified carbon fiber microelectrodes. Anal. Chem. 68 (1996) 4358-4364.

[4] N.F. Shram, L.I. Netchiporouk, C. Martelet, N. Jaffrezic-Renault, R. Cespuglio, Brain glucose: voltammetric determination in normal and hyperglycaemic rats using a glucose microsensor. NeuroReport 8 (1997) 1109-1112.

[5] Y. Hu, G.S. Wilson, Rapid changes in local extracellular rat brain glucose observed with an in vivo glucose sensor. J. Neurochem. 68 (1997) 1745-1752.

[6] Y. Hu, G.S. Wilson, A temporary local energy pool coupled to neuronal activity: fluctuations of extracellular lactate levels in rat brain monitored with rapid-response enzyme-based sensor. J. Neurochem. 69 (1997) 1484-1490.

[7] N.F. Shram, L.I. Netchiporouk, C. Martelet, N. Jaffrezic-Renault, C. Bonnet, R. Cespuglio, In vivo voltammetric detection of rat brain lactate with carbon fiber microelectrodes coated with lactate oxidase. Anal. Chem. 70 (1998) 2618-2622.

[8] Y. Ikegami, M. Maeda, A. Yokota, Y. Hayashida, Cerebral extracellular lactate concentration and blood flow during chemical stimulation of the nucleus tractus solitarii in anesthetized rats. Brain Res. 758 (1997) 33-38.

[9] M.G. Garguilo, A.C. Michael, Amperometric microsensors for monitoring choline in the extracellular fluid of brain. J. Neurosci. Methods 70 (1996) 73-82.

[10] M.G. Garguilo, A.C. Michael, An enzyme-modified microelectrode that detects choline injected locally into brain tissue. J. Am. Chem. Soc. 115 (1993) 12218-12219.

[11] M.G. Garguilo, A.C. Michael, Optimization of amperometric microsensors for monitoring choline in the extracellular fluid of brain tissue. Anal. Chim. Acta 307 (1995) 291-299.

[12] M.G. Garguilo, A.C. Michael, Quantitation of choline in the extracellular fluid of brain tissue with amperometric microsensors. Anal. Chem. 66 (1994) 2621-2629.

[13] Y. Hu, K.M. Mitchell, F.N. Albahadily, E.K. Michaelis, G.S. Wilson, Direct measurement of glutamate release in the brain using a dual enzyme-based electrochemical sensor. Brain Res. 659 (1994) $117-125$.

[14] M.C. Walker, P.T. Galley, M.L. Errington, S.D. Shorvon, J.G.R. Jefferys, Ascorbate and glutamate release in the rat hippocampus after perforant path stimulation: a "dialysis electrode" study. J. Neurochem. 65 (1995) 725-731.

[15] S. Asai, Y. Iribe, T. Kohno, K. Ishikawa, Real time monitoring of biphasic glutamate release using dialysis electrode in rat acute brain ischemia. NeuroReport 7 (1996) 1092-1096.

[16] N.V. Kulagina, L. Shankar, A.C. Michael, Monitoring glutamate and ascorbate in the extracellular space of brain tissue with electrochemical microsensors. Anal. Chem. 71 (2000) 5093-5100.

[17] J.P. Lowry, M. Fillenz, Evidence for uncoupling of oxygen and glucose utilization during neuronal activation in rat striatum. J. Physiol. (London) 498 (1997) 497-501.

[18] J.P. Lowry, R.D. O'Neill, M.G. Boutelle, M. Fillenz, Continuous monitoring of extracellular glucose concentrations in the striatum of freely moving rats with an implanted glucose biosensor. J. Neurochem. 70 (1998) 391-396.

[19] M. Fillenz, J.P. Lowry, The relation between local cerebral blood flow and extracellular glucose concentration in rat striatum. Exp. Physiol. 83 (1998) 233-238.

[20] M. Fillenz, J.P. Lowry, Studies of the source of glucose in the extracellular compartment of the rat brain. Dev. Neurosci. 20 (1998) $365-368$.

[21] J.P. Lowry, R.D. O'Neill, Partial characterization in vitro of glucose oxidase-modified poly(phenylenediamine)-coated electrodes for neurochemical analysis in vivo. Electroanalysis 6 (1994) 369-379.

[22] J.P. Lowry, K. McAteer, S.S. El Atrash, A. Duff, R.D. O'Neill, Characterization of glucose oxidase-modified poly(phenylenediamine)-coated electrodes in vitro and in vivo: homogeneous interference by ascorbic acid in hydrogen peroxide detection. Anal. Chem. 66 (1994) 1754-1761.

[23] J.P. Lowry, K. McAteer, S.S. El Atrash, R.D. O'Neill, Efficient glucose detection in anaerobic solutions using an enzyme-modified electrode designed to detect $\mathrm{H}_{2} \mathrm{O}_{2}$ : implications for biomedical applications. J. Chem. Soc., Chem. Commun. (21) (1994) 24832484.

[24] J.P. Lowry, M. Miele, R.D. O'Neill, M.G. Boutelle, M. Fillenz, An amperometric glucose-oxidase/poly(o-phenylenediamine) biosensor for monitoring brain extracellular glucose: in vivo characterization in the striatum of freely moving rats. J. Neurosci. Methods 79 (1997) $65-74$.

[25] R.D. O'Neill, R.A. Grunewald, M. Fillenz, W.J. Albery, Linear sweep voltammetry with carbon paste electrodes in the rat striatum. Neuroscience 7 (1982) 1945-1954.

[26] J.P. Lowry, M.G. Boutelle, M. Fillenz, Measurement of brain tissue oxygen at a carbon paste electrode can serve as an index of increases in regional cerebral blood flow. J. Neurosci. Methods 71 (1997) $177-182$.

[27] C. Bourdillon, V. Thomas, D. Thomas, Electrochemical study of D-glucose oxidase autoinactivation. Enzyme Microb. Technol. 4 (1982) 175-180.

[28] Y.N. Zhang, G.S. Wilson, In vitro and in vivo evaluation of oxygen effects on a glucose oxidase based implantable glucose sensor. Anal. Chim. Acta 281 (1993) 513-520.

[29] J.P. Lowry, M.G. Boutelle, R.D. O’Neill, M. Fillenz, Characterization of carbon paste electrodes in vitro for simultaneous amperometric measurement of changes in oxygen and ascorbic acid concentrations in vivo. Analyst 121 (1996) 761-766.

[30] S. Wolfensohn, M. Lloyd, Handbook of Laboratory Animal Management and Welfare. Oxford Univ. Press, Oxford, 1994.

[31] A.E. Fray, R.J. Forsyth, M.G. Boutelle, M. Fillenz, The mechanisms controlling physiologically stimulated changes in rat brain glucose and lactate: a microdialysis study. J. Physiol. (London) 496 (1996) 49-57.

[32] G. Paxinos, C. Watson, The Rat Brain in Stereotaxic Coodinates. Academic Press, Sydney, 1986.

[33] R.D. O'Neill, Sensor-tissue interactions in neurochemical analysis with carbon paste electrodes in vivo. Analyst 118 (1993) 433-438.

[34] D.B. Morton, P.H.M. Griffiths, Guidelines on the recognition of pain and discomfort in experimental animals and an hypothesis for assessment. Vet. Rec. 116 (1985) 431-436.

[35] T. Kawamoto, T. Hobara, H. Kobayashi, S. Iwamoto, T. Saki, T. Takano, Y. Miyazaki, The metabolite ratio as a function of chloral hydrate dose and intracellular redox state in the perfused rat liver. Pharmacol. Toxicol. 60 (1987) 325-329.

[36] R. Tao, S.B. Auerbach, Anaesthetics block morphine-induced increases in serotonin release in rat CNS. Synapse 18 (1994) 307-314.

[37] D.M. Lovinger, S.A. Zimmerman, M. Levitin, M.V. Jones, N.L. Harrison, Trichloroethanol potentiates synaptic transmission mediated by $\gamma$-aminobutyric acid $_{\mathrm{A}}$ receptors in hippocampal neurons. J. Pharmacol. Exp. Ther. 264 (1993) 1097-1103.

[38] R.E. Study, J.L. Barker, Diazepam and (-)-pentobarbital: fluctuation analysis reveals different mechanisms for potentiation of gamma-aminobutyric acid responses in cultured central neurons. Proc. Natl. Acad. Sci. U. S. A. 78 (1981) 7180-7184. 
[39] M. Irifune, T. Shimzu, M. Nomoto, T. Fukuda, Ketamine-induced anesthesia involves the $N$-methyl-D-aspartate receptor-channel complex in mice. Brain Res. 596 (1992) 1-9.

[40] K.J. Field, W.J. White, C.M. Lang, Anaesthetic effects of chloral hydrate, pentobarbitone and urethane in adult male rats. Lab. Anim. 27 (1993) 258-269.

[41] J.J. Grome, G. McCulloch, The effects of chloral hydrate anesthesia on the metabolic response in the substantial nigra to apomorphine. Brain Res. 214 (1981) 223-228.

[42] H.E. Savaki, L. Davidsen, C. Smith, L. Sokoloff, Measurement of free glucose turnover in brain. J. Neurochem. 35 (1980) 495-502.

[43] A. Gjedde, M. Rasmussen, Pentobarbital anaesthesia reduces blood-brain glucose transfer in the rat. J. Neurochem. 35 (1980) $1382-1387$.

[44] U. Lindauer, A. Villringer, U. Dirnagl, Characterization of CBF response to somatosensory stimulation: model and influence of anesthetics. Am. J. Physiol. 264 (1993) H1223-H1228.

[45] S. Bjorkman, J. Akeson, F. Nilsson, K. Messeter, B. Roth, Ketamine and midazolam decrease cerebral blood flow and consequently their own rate of transport to the brain: an application of mass balance pharmacokinetics with a changing regional blood flow. J. Pharmacokinet. Biopharm. 20 (1992) 637-652.

[46] S. Strebel, M. Kaufmann, L. Maitre, H.G. Schaefer, Effects of ketamine on cerebral blood flow velocity in humans. Influence of pretreatment with midazolam or esmolol. Anaesthesia 50 (1995) 223-228.

[47] L.K. Fellows, M.G. Boutelle, M. Fillenz, Extracellular brain glucose levels reflect local neuronal activity: a microdialysis study in awake, freely moving rats. J. Neurochem. 59 (1992) 2141-2147.

[48] P.F. Morrison, P.M. Bungay, J.K. Hsiao, B.A. Ball, I.N. Mefford, R.L. Dedrick, Quantitative microdialysis: analysis of transients and application to pharmacokinetics in brain. J. Neurochem. 57 (1991) 103-119.
[49] A. Vahabzadeh, M. Fillenz, Comparison of stress-induced changes in noradrenergic and serotonergic neurons in the rat hippocampus using microdialysis. Eur. J. Neurosci. 6 (1994) 1205-1212.

[50] B.S. Bunney, J.R. Walters, R.H. Roth, C.K. Aghajanian, Dopaminergic neurons: effects of antipsychotic drugs and amphetamine on single cell activity. J. Pharmacol. Exp. Ther. 185 (1973) 560-571.

[51] G. Mereu, F. Fadda, G.L. Gessa, Ethanol stimulates the firing rate of nigral dopaminergic neurons in unanesthetized rats. Brain Res. 292 (1984) 63-69.

[52] J. Petrinec, J. Guadalupe, B. Fumero, L. Gonzales-Mora, M. Mas, Effects of different anaesthetics on striatal dopaminergic activity as assessed by in vivo voltammtery, in: J.L.L. Gonzales-Mora, R. Borges, M. Mas (Eds.), Monitoring Molecules in Neuroscience. University of La Laguna, 1996, pp. 293-294.

[53] H. Chen, S.B. Kandasamy, Effect of chloral hydrate on in vivo $\mathrm{KCl}$-induced striatal dopamine release in the rat. Neurochem. Res. 21 (1996) 695-700.

[54] M.E. Hamilton, A. Mele, A. Pert, Striatal extracellular dopamine in conscious vs. anesthetized rats: effects of chloral hydrate anesthetic on response to drugs of different classes. Brain Res. 597 (1992) 1-7.

[55] L. Sokoloff, The brain as a chemical machine. Prog. Brain Res. 94 (1992) 19-33.

[56] P.J. Magistretti, L. Pellerin, Cellular bases of brain energy metabolism and their relevance to functional brain imaging: evidence for a prominent role of astrocytes. Cereb. Cortex 6 (1996) 50-61.

[57] M. Shiraishi, Y. Kamiyama, P.C. Hüttemeier, H. Benveniste, Extracellular glutamate and dopamine measured by microdialysis in the rat striatum during blockade of synaptic transmission in anesthetized and awake rats. Brain Res. 759 (1997) 221-227.

[58] J.A. Clemens, L.A. Phebus, Changes in brain chemistry produced by dopaminergic agents: in vivo electrochemical monitoring reveals opposite changes in anaesthetized vs. unanaesthetized rats. Brain Res. 267 (1983) 183-186. 